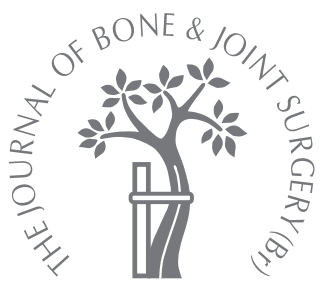

R. Birch, N. Ahad, H. Kono, S. Smith

From The Royal National Orthopaedic Hospital, Stanmore, England

\section{Repair of obstetric brachial plexus palsy}

\author{
RESULTS IN 100 CHILDREN
}

This is a prospective study of 107 repairs of obstetric brachial plexus palsy carried out between January 1990 and December 1999. The results in 100 children are presented. In partial lesions operation was advised when paralysis of abduction of the shoulder and of flexion of the elbow persisted after the age of three months and neurophysiological investigations predicted a poor prognosis. Operation was carried out earlier at about two months in complete lesions showing no sign of clinical recovery and with unfavourable neurophysiological investigations.

Twelve children presented at the age of 12 months or more; in three more repair was undertaken after earlier unsuccessful neurolysis. The median age at operation was four months, the mean seven months and a total of 237 spinal nerves were repaired.

The mean duration of follow-up after operation was 85 months (30 to 152). Good results were obtained in $33 \%$ of repairs of $\mathrm{C5}$, in $55 \%$ of $\mathrm{C6}$, in $\mathbf{2 4} \%$ of $\mathrm{C7}$ and in $57 \%$ of operations on $\mathrm{C} 8$ and T1. No statistical difference was seen between a repair of C5 by graft or nerve transfer.

Posterior dislocation of the shoulder was observed in $\mathbf{3 0}$ cases. All were successfully relocated after the age of one year. In these children the results of repairs of $\mathrm{C} 5$ were reduced by a mean of $\mathbf{0 . 8}$ on the Gilbert score and $\mathbf{1 . 6}$ on the Mallett score. Pre-operative electrodiagnosis is a reliable indicator of the depth of the lesion and of the outcome after repair. Intra-operative somatosensory evoked potentials were helpful in the detection of occult intradural (pre-ganglionic) injury.
The first nerve root repairs for obstetric brachial plexus palsy were recorded early in the 20th century. ${ }^{1-5}$ The outcome following resection of the neuroma and end-to-end or end-toside suture was not good. Later authors were sceptical about the benefits of operative repair. ${ }^{6,7}$ However, Narakas, ${ }^{8}$ and Morelli, Raimondi and Saporiti ${ }^{9}$ revived the procedure, achieving some good results following microsurgical grafting, but the indications for operation remain uncertain. There is still no general agreement about the measurement of outcome and it remains difficult to assess the benefits of repair. Selection for operation is guided by the extent of the lesions, the rate of recovery and the results of radiological investigations and electrodiagnosis.

Narakas ${ }^{10}$ classified the injuries (Table I) and showed that the extent of the injury was a useful indicator for spontaneous recovery.

Evans-Jones et $\mathrm{al}^{11}$ published the first national survey of the incidence, risk factors and recovery in the first six months of life for babies born with obstetric brachial plexus palsy between April of 1998 and March 1999. The incidence was 0.42 per 1000 live births in
Correspondence should be sent to Professor R. Birch; e-mail:

benita.patel@rnoh.nhs.uk

(C)2005 British Editorial

Society of Bone and

Joint Surgery

doi:10.1302/0301-620X.87B8.

$15975 \$ 2.00$

$J$ Bone Joint Surg $[B r]$

2005;87-B:1089-95.

Received 6 September 2004;

Accepted after revision

7 April 2005

Table I. Classification system described by Narakas ${ }^{10}$

\begin{tabular}{llll}
\hline Group & Nerves injured & Presentation & Likely outcome \\
\hline 1 & C5/6 & $\begin{array}{l}\text { Paralysis of shoulder, absent elbow } \\
\text { flexion }\end{array}$ & Spontaneous recovery in over 80\% \\
2 & C5, C6, C7 & $\begin{array}{l}\text { As above with wrist drop } \\
\text { Complete paralysis }\end{array}$ & $\begin{array}{l}\text { Good hand. Good shoulder and elbow in about 70\%. } \\
\text { Good hand in majority }\end{array}$ \\
3 & All & $\begin{array}{l}\text { Complete paralysis. Bernard-Horner sign } \\
\text { Limb may be atonic, marbled and cold. }\end{array}$ & $\begin{array}{l}\text { Full recovery is extremely rare. Severe defects } \\
\text { throughout the limb likely. }\end{array}$ \\
\hline
\end{tabular}

* shortening of the limb may be severe in group 4, with atrophy of the hand. Occasionally the ipsilateral foot is smaller, suggesting an element of cord lesion. 
Table II. Neurophysiological findings in obstetric brachial plexus palsy adapted from Smith ${ }^{20,21}$

\begin{tabular}{|c|c|c|c|}
\hline Type & NAP $^{*}$ & $\mathrm{EMG}^{\dagger}$ & Lesion \\
\hline A & Normal & $\begin{array}{l}\text { No spontaneous activity, reduced number } \\
\text { of normal motor units, increased firing rates }\end{array}$ & Conduction block \\
\hline B (favourable) & Normal or $>50 \%$ of uninjured side & $\begin{array}{l}\text { Relatively good motor unit recruitment, } \\
\text { mixture of normal and polyphasic units } \\
\text { suggesting collateral re-innervation }\end{array}$ & $\begin{array}{l}\text { Mild axonal (degenerative) lesion } \\
\text { (axonotmesis) }\end{array}$ \\
\hline B (unfavourable) & Absent or $<50 \%$ of uninjured side & $\begin{array}{l}\text { Normal units few or absent, collateral } \\
\text { re-innervation }\end{array}$ & Significant axonal lesion (neurotmesis) \\
\hline C & $\begin{array}{l}\text { Absent (or present in pre-ganglionic } \\
\text { lesion) }\end{array}$ & $\begin{array}{l}\text { Spontaneous activity, nascent units, } \\
\text { poor recruitment }\end{array}$ & $\begin{array}{l}\text { Severe axonal injury (neurotmesis or } \\
\text { pre-ganglionic) }\end{array}$ \\
\hline
\end{tabular}

* NAP, nerve action potential

† EMG, electromyographic

the United Kingdom and the Republic of Ireland. Of the 255 group 1 and group 2 lesions, 143 had fully recovered at six months and there was partial recovery in the remainder. None of the 19 group 3 and 4 lesions had recovered fully by six months and six babies showed no recovery at all. Bisinella and Birch ${ }^{12}$ studied 74 of 323 cases in a National Census seen in one unit over a period of two years. Full recovery was seen in 21 of the 28 group 1 lesions, in 14 of the 38 group 2 and in 4 of the eight group 3 and 4 injuries. Nerves were repaired in seven infants. An operation to correct posterior dislocation of the shoulder was necessary in $20(27 \%)$ of the 74 children studied.

These studies confirmed that the extent of the lesion is a valuable guide to prognosis, which is much better for group 1 than for group 4 injuries.

The speed of recovery provides further information about prognosis. Recovery in groups 1 and 2 lesions is often poor if the biceps remains paralysed at three months. ${ }^{13}$ Scoring systems have been developed based on the recovery of different muscles in the upper limb. ${ }^{14-17}$ Myelography and CT myelography were used by Slooff and Blaauw $^{18}$ and Blaauw, Slooff and Muhlig ${ }^{19}$ to analyse the particular difficulties of obstetric brachial plexus palsy in breech deliveries, which are associated with a much higher incidence of nerve lesions. These are bilateral in $25 \%$ and may be complicated by phrenic palsy in $25 \%$. Contrast imaging showed intradural abnormalities of the upper nerves of the brachial plexus in 47 of 54 cases. Smith ${ }^{20,21}$ assessed the depth of the lesion in over 700 infants through a combination of mixed nerve action potential recordings from the median and ulnar nerves in the forearm and electromyographic (EMG) sampling of selected muscles. Her conclusions and classification (Table II) have been shown to be valid in most cases. Bisinella, Birch and Smith ${ }^{22}$ matched the neurophysiological predictions with the final outcome in 199 spinal nerves in 73 children whose recovery was slow. In all these babies biceps remained paralysed at the age of three months. The predictions for $\mathrm{C} 6$ and $\mathrm{C} 7$ were confirmed in $92 \%$ and $96 \%$ of cases respectively and those for $\mathrm{C} 5$ in $78 \%$. There was a statistically significant association between C5 lesions recovering less well than predicted and associated posterior dislocation of the shoulder, seen in 33 of the children.
The largest reported series of results of repair is that of Gilbert. ${ }^{23,24}$ Group 1 and 2 lesions were generally good and $75 \%$ of children with total lesions regained useful finger flexion and $50 \%$ some function in the small muscles of the hand. Gilbert introduced two important techniques of repair. With avulsion of C7, C8 and T1 the hand is re-innervated by transfer of the proximal stumps of the ruptured C5 and C6 nerves to the lower trunk. Selective re-innervation of the ventral root of the avulsed nerves is achieved by transfer of adjacent nerves such as the spinal accessory. We have used this technique in appropriate cases. Chen ${ }^{25}$ reviewed 65 repairs performed in our unit before 1990, showing poor results from re-innervation of the lower trunk by intercostal transfer.

Recovery after repair is slow. Improvement continues for at least three years after repair of the upper trunk and hand function will progress for longer. ${ }^{24}$ Anand and Birch $^{26}$ described the outcome in 24 group 4 cases. Eleven of the 20 babies operated on were eligible for inclusion in the present study. Four who had not had surgery presented later in life with neither power nor sensation in the hand. Operative repair was undertaken in 20 infants. Only three of 120 spinal nerves were intact. There were 47 avulsions, 58 ruptures, and 12 lesions in continuity. Quantitative measurements of cutaneous sensation and cholinergic sympathetic recovery were carried out between 46 and 121 months after surgery. Useful motor function was restored in the hand in ten of the 20 cases. Recovery of sensibility greatly exceeded that of skeletal muscle and cholinergic sympathetic function, with recovery to normal limits in all dermatomes for at least one modality in 16 hands. These children showed perfect localisation of restored sensation in the dermatomes of avulsed spinal nerves which had been re-innervated by intercostal nerves transferred from remote spinal segments. This degree of plasticity in the immature central nervous system may be a factor in the remarkable absence of neuropathic pain in obstetric brachial plexus palsy unlike after traction lesions in adults.

\section{Patients and Methods}

Between January 1990 and December 1999 we carried out 107 repairs of obstetric brachial plexus palsy in 100 children. There were 55 boys and 45 girls. The lesions were 
Table III. The five categories of lesion of individual spinal nerves

\begin{tabular}{|c|c|c|c|c|c|}
\hline Lesion & $\begin{array}{l}\text { Pre-operative neuro- } \\
\text { physiological type }\end{array}$ & $\begin{array}{l}\text { Intra-operative } \\
\text { SSEP* at } \\
\text { foramen }\end{array}$ & $\begin{array}{l}\text { Intra-operative } \\
\text { SSEP* stimulating } \\
\text { distal to lesion }\end{array}$ & $\begin{array}{l}\text { Muscle response } \\
\text { evoked by } \\
\text { stimulation at } \\
\text { foramen }\end{array}$ & Appearance \\
\hline Recovering rupture & B (favourable) & Normal & $>50 \%$ & Strong & $\begin{array}{l}\text { Fusiform neuroma, normal nerve } \\
\text { proximally }\end{array}$ \\
\hline Rupture & B (unfavourable) & Normal & $<50 \%$ & Weak & $\begin{array}{l}\text { Hard 'double humped' neuroma. } \\
\text { Normal nerve proximally }\end{array}$ \\
\hline $\begin{array}{l}\text { Rupture with partial } \\
\text { pre-ganglionic lesion of } \\
\text { intradural elements }\end{array}$ & B (unfavourable) or C & Diminished & $\begin{array}{l}\text { Diminished or } \\
\text { absent }\end{array}$ & Weak & $\begin{array}{l}\text { Diffuse longitudinal fibrosis, } \\
\text { nerve coiled up }\end{array}$ \\
\hline $\begin{array}{l}\text { Incomplete pre-ganglionic or } \\
\text { selective pre-ganglionic of } \\
\text { ventral and dorsal roots }\end{array}$ & B (unfavourable) or C & $\begin{array}{l}\text { Diminished or } \\
\text { absent }\end{array}$ & $\begin{array}{l}\text { Diminished or } \\
\text { absent }\end{array}$ & Weak or absent & Atrophy of nerve at foramen \\
\hline Complete pre-ganglionic & $\mathrm{C}$ & Absent & Absent & Absent & Dorsal root ganglion evident \\
\hline
\end{tabular}

* SSEP, somatosensory evoked potentials

equally distributed between the right and left upper limbs. Five babies were excluded from the review because of inadequate data and two died of unrelated causes.

The object of repair in group 1 and 2 lesions was the restoration of shoulder function and elbow flexion. In the groups 3 and 4 cases, the primary object of surgery was the restoration of hand function. Operation was advised when poor clinical recovery was matched by unfavourable neurophysiological predictions. Neurophysiological studies (Table II) were performed in group 1 and 2 lesions at the age of 10 to 14 weeks. Persisting paralysis of type B (unfavourable) or $\mathrm{C}$ was an indication for operation for C5; persisting paralysis of type $\mathrm{C}$ was an indication for operation for C6 and C7. Neurophysiological investigations were performed at six to eight weeks in complete lesions. After 1997, MR scanning of the neck and spinal cord was done in 11 group 4 lesions. In these, operation was indicated where poor clinical recovery was matched by type C findings and radiological evidence of intradural injury. The technique of repair has been described elsewhere. ${ }^{27}$ In brief, the brachial plexus is exposed. Display of C8 and T1 requires division of scalenus anterior and exposure of the subclavian artery. Somatosensory evoked potentials are recorded from each spinal nerve at its emergence from the foramen and then again from nerve trunks distal to the demonstrated lesion. Distal muscular response to stimulation of the spinal nerve and of its derivative trunks is noted. Recording of measurable somatosensory evoked potentials from stimulation of a nerve trunk distal to the lesion was a contra-indication for excision and grafting. The lesions of individual spinal nerves were graded into 5 categories (Table III).

The lesion in obstetric brachial plexus palsy is complex. It is caused by a longitudinal stretch along the spinal nerves extending from the spinal cord to the clavicle and there may be extensive fibrosis around the damaged plexus. The lesion of the nerve ranges from a recoverable stretch to a definite rupture, or of obvious avulsion when the dorsal root ganglion is seen in the posterior triangle of the neck. There is always some regeneration of fibres across post-ganglionic ruptures. Two intermediate lesions are perplexing. There may be an elongated fibrosed nerve in which there is some conduction. In these there is usually some recovery, but this is incomplete. A 'silent' nerve may be encountered. It is apparently intact but has neither peripheral or central conduction. While some of these may recover, many do not.

Ruptured nerves were repaired by grafts of cutaneous nerves taken from the forearm and arm, supplemented by the sural nerve when three roots required repair. In complete lesions with avulsion of the lowest two or three nerves of the brachial plexus, the proximal stumps of post ganglionic ruptures of $\mathrm{C} 5$ and $\mathrm{C} 6$ were transferred to the middle and lower trunks. ${ }^{23}$ Accessory to suprascapular nerve transfer was performed regularly in severe lesions of C5, and intercostal nerves were used to re-innervate the lateral cord in similarly severe lesions of the lowest three nerves, when C5 and C6 were transferred to the middle and lower trunks. With avulsion of one or two spinal nerves, selective transfer of the accessory or lateral pectoral nerves to the ventral root of the avulsed nerve and of supraclavicular nerves to the dorsal part of the avulsed spinal nerve after resection of the dorsal root ganglion was carried out. Repairs were secured by fibrin clot glue and sutures were used for nerve transfers. The infants were immobilised in a plaster-of-Paris cowl for between three and four weeks. The numbers of grafts ranged from five to 13 , and their length from 1.8 to $4 \mathrm{~cm}$. Histological and immunohistochemical studies were carried out on nerve stumps and dorsal root ganglia.

Follow-up and assessment. After removal of the plaster cowl parents were shown exercises to regain passive movement in all joints, especially the shoulder. Regular reports from local therapists provided valuable information about recovery and the onset of fixed deformity. The children were reviewed by one of us (RB) at intervals of no more than six months for two years and then annually until the age of seven years. The methods used for recording function have been fully described elsewhere. ${ }^{12,27-31}$ For the shoulder Gilbert's system ${ }^{28}$ grades function from 0 (paralysis) to 6 (normal). Mallett's system ${ }^{29}$ awards points for five functions at the shoulder, a score of 15 implies a very good, but not necessarily a normal shoulder, a score of 4 indicates 
Table IV. Results of the repair for each spinal nerve

\begin{tabular}{|c|c|c|c|c|}
\hline Result & $\mathrm{C5}^{*}$ & C6 & C7 & $\mathrm{C} 8$ and $\mathrm{T} 1^{\dagger}$ \\
\hline Good & $\begin{array}{l}\text { Gilbert } 4+\text { or better } \\
\text { Mallett } 13 \text { or better }\end{array}$ & $\begin{array}{l}\text { Full flexion/supination } \\
\text { Biceps MRC } 5\end{array}$ & Full extension wrist & $\begin{array}{l}\text { Raimondi } 4 \text { or 5; digital extension and flexion - } \\
\text { intrinsic balance. Hands used appropriately in } \\
\text { bi-manual activity. }\end{array}$ \\
\hline Fair & $\begin{array}{l}\text { Gilbert 3+ } \\
\text { Mallett 11, } 12\end{array}$ & $\begin{array}{l}\text { Functional flexion } \\
\text { MRC } 3+\text {. Supination to } 45^{\circ}\end{array}$ & Wrist extension MRC 3 & $\begin{array}{l}\text { Raimondi 3; digital flexion providing simple or } \\
\text { vestigial grasp. Hand is used to support or help the } \\
\text { uninjured side }\end{array}$ \\
\hline Poor & Less than above & Less than above & Less than above & Less than above, hand with no or vestigial function \\
\hline
\end{tabular}

Table V. Operative findings in the 500 spinal nerves explored in 100 babies

\begin{tabular}{|c|c|c|c|c|c|c|c|}
\hline Type of lesion & C5 & C6 & $\mathrm{C7}$ & C8 & T1 & Total & $\begin{array}{l}\text { Number } \\
\text { repaired }\end{array}$ \\
\hline Intact & 0 & 5 & 15 & 43 & 47 & 110 & 0 \\
\hline 1 & 8 & 5 & 31 & 14 & 16 & 74 & 1 \\
\hline 2 & 82 & 50 & 11 & 0 & 0 & 143 & 136 \\
\hline 3 & 4 & 14 & 10 & 3 & 2 & 33 & 25 \\
\hline 4 & 2 & 6 & 12 & 16 & 11 & 47 & 17 \\
\hline 5 & 4 & 20 & 21 & 24 & 24 & 93 & 58 \\
\hline Total of nerves & 100 & 100 & 100 & 100 & 100 & 500 & \\
\hline Total of lesions & 100 (8 favourable) & 95 (5 favourable) & 85 (31 favourable) & 57 (14 favourable) & 53 (16 favourable) & 390 (74 favourable) & \\
\hline Number repaired & 87 & 74 & 29 & 28 & 19 & & 237 \\
\hline
\end{tabular}

paralysis. Our own system records the active and passive range of glenohumeral and thoracoscapular movement and of pronation and supination of the forearm. Our modification of the Gilbert score is heavily weighted towards medial contracture of the shoulder which usually indicates dislocation.

Elbow flexion was graded by the system of Gilbert and Raimondi ${ }^{30}$ which ranges from 0 (paralysis) to 5 (complete active flexion and extension). Function of the hand was graded from 0 (paralysis) to 5 in which there is complete active flexion and extension of the wrist and fingers, strong intrinsic muscle function and active pronation and supination in excess of $90^{\circ}$, as described by Raimondi. ${ }^{31}$

With repairs of the lower trunk quantitative measurement of sensory and cholinergic sympathetic function was undertaken at a minimum of five years after operation. ${ }^{26}$ Limb growth was recorded by measuring from the acromion to the olecranon, from the olecranon to the ulnar styloid and of the length and breadth of the thumb and selected digits. Growth of the hand was measured by drawing the outline of the hands and by plethysmography.

The results of the repair for each spinal nerve were graded (Table IV) before any necessary subsequent palliative musculotendinous transfer to enhance elbow flexion or function of the wrist and hand. They were graded after relocation of the dislocated shoulder in 30 children because this serious deformity blocks the expression of neurological recovery throughout the upper limb.

One of us (HK) analysed the results in 70 of the children presented here in 1999. The earlier findings have been confirmed but a trend to continuing improvement was found especially for hand function.
Table VI. Results of repair of spinal nerves

\begin{tabular}{llllll}
\hline & C5 & C6 & C7 & C8 and T1 \\
\hline $\begin{array}{l}\text { Number of unfavourable } \\
\text { lesions }\end{array}$ & 92 & 90 & 54 & 80 \\
Total repairs & 87 & 74 & 29 & 47 \\
$\quad$ Good (\%) & $29(33)$ & $41(55)$ & $7(24)$ & $27(57)$ \\
$\quad$ Fair (\%) & $42(48)$ & $19(26)$ & $10(35)$ & $17(36)$ \\
$\quad$ Poor (\%) & $16(19)$ & $14(19)$ & $12(41)$ & $3(7)$ \\
\hline
\end{tabular}

\section{Results}

The mean birth weight of the 96 cephalic deliveries was 4.3 $\mathrm{kg}$ against a regional mean of $3.03 \mathrm{~kg}$ and $57 \%$ were complicated by shoulder dystocia. There were three breech deliveries and one by Caesarean section.

According to the Narakas grading system ${ }^{10}$ two of the children were in group 1, 36 in group 2, 12 in group 3 and 50 in group 4.

Table $\mathrm{V}$ describes the state of the 500 spinal nerves in this series of babies. The most common lesion in C5 and C6 was a post-ganglionic rupture, type 2 . Type 5 , complete avulsion, was the most common finding in C8 and T1.

We did not repair 79 nerves with type 2, 3, 4 and 5 lesions. Lesions of C8 and T1 which demonstrated any signs of recovery was left as were some C7 injuries. In severe cases of multiple avulsions one or even two nerves could not be repaired.

Neurophysiological evidence. The relationship between the pre-operative neurophysiological studies and the findings at operation was statistically significant (Pearson's correlation, $\mathrm{p}<0.001$ ) (Table VI). Nerves which were intact or showing strong recovery were not analysed before opera- 
Table VII. Results of repair of C5 and C 6 by Narakas grade ${ }^{8}$ of neurological lesion 161 repairs

\begin{tabular}{|c|c|c|c|c|}
\hline \multirow[b]{2}{*}{ Outcome } & \multicolumn{2}{|l|}{ C5 (87 repairs) } & \multicolumn{2}{|l|}{ C6 (74 repairs) } \\
\hline & $\begin{array}{l}\text { Narakas grade } \\
1,2 \text { and } 3\end{array}$ & 4 & $\begin{array}{l}\text { Narakas grade } \\
\text { 1, } 2 \text { and } 3\end{array}$ & 4 \\
\hline Good (\%) & $20(40)$ & $9(24)$ & $27(64)$ & $14(44)$ \\
\hline Fair (\%) & $21(42)$ & $21(57)$ & $9(22)$ & $10(31)$ \\
\hline \multirow[t]{2}{*}{ Poor (\%) } & $9(18)$ & 7 (19) & $6(14)$ & $8(25)$ \\
\hline & 50 & 37 & 42 & 32 \\
\hline
\end{tabular}

tion but the remaining 350 were assessed. When the predictions were matched with the findings at surgery it appeared that the neurophysiological evidence was unduly optimistic in $19 \%$ of the B (favourable) type, in $17 \%$ of the B (unfavourable) type and in $9 \%$ of type C. The prediction of type $\mathrm{C}$ was confirmed in 177 of 191 spinal nerves. In these, rupture, complete avulsion or a mixture of both (types 2, 3, 4,5 ) was found. However, the neurophysiological findings in two of these spinal nerves early in the series were misinterpreted as indicating a lesion more favourable than was the case. In six more spinal nerves where an overoptimistic prediction was given, a severe lesion was found in an adjacent nerve, usually $\mathrm{C} 7$ or T1, one of which was either ruptured or avulsed. It is possible that this is an indication of the variation of the distribution of the individual spinal nerves.

The neurophysiological evidence appeared to be unduly pessimistic in 34 spinal nerves. When these nerves, in which rupture or worse had been predicted, were exposed, they appeared to be damaged less seriously. None were repaired; 22 went on to final recovery as had been predicted and 12 more did better than anticipated.

The correlation between the neurophysiological prediction and the final outcome was unexpected, since $50 \%$ of the repairs of type B (unfavourable) lesions were graded as good but only $34 \%$ of repairs in type $\mathrm{C}$ reached this level. This confirms the usefulness of intra-operative neurophysiological studies. The validity of such investigations in determining the prognosis in cases which did not have an operation has already been demonstrated. ${ }^{22}$

Repair by the level of the spinal nerves (Table VI) C5. There were 87 repairs in 92 unfavourable lesions, of which four were complete avulsions. A good result was achieved in $33 \%$. The operation failed in 16 nerves (19\%). In the 30 children who required operation for dislocation of the shoulder the neurological function was less good even after successful relocation. The mean Gilbert and Mallett scores in children without dislocation were 3.3 and 12.4 respectively; the mean scores for those who required later relocation and operations were 2.5 and 10.8 respectively. Fibrosis provoked by the deformity, by necessary operation and post-operative immobilisation may contribute towards this difference in outcome.

C6. There were 74 repairs in 90 unfavourable lesions. The failure rate was $19 \%$ (14 nerves). In 26\% (19 nerves) flex-

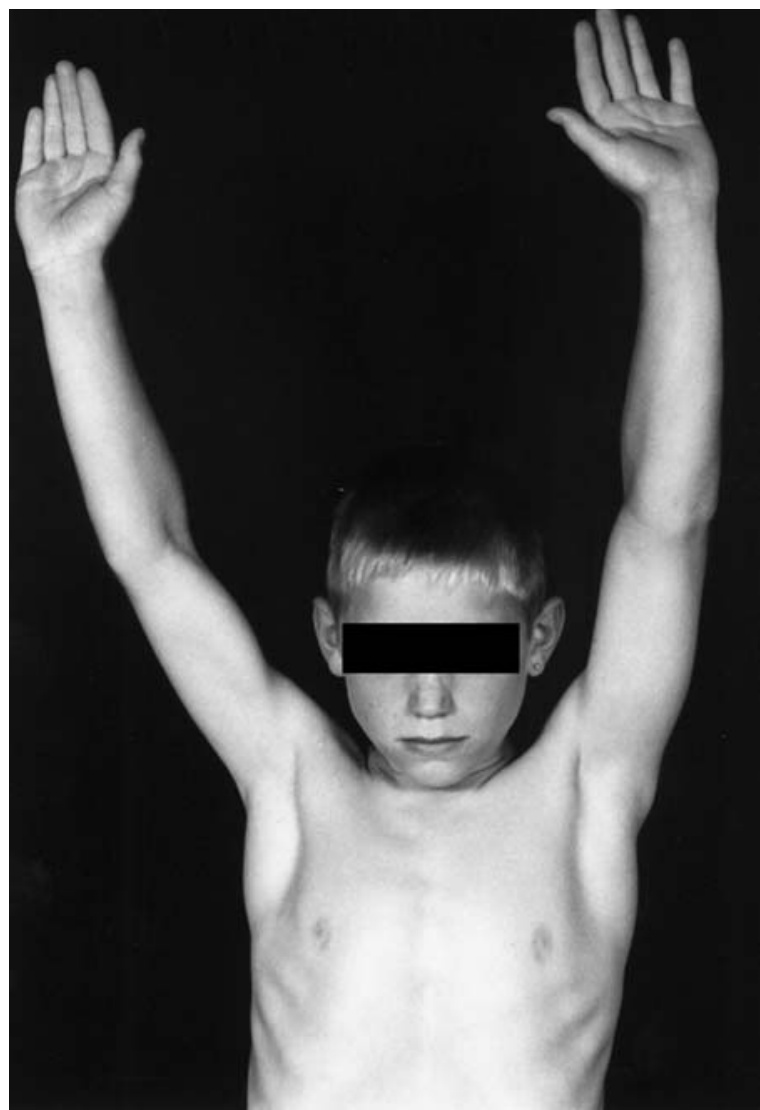

Fig. 1

Photograph of an eight-year-old boy who had a group 2 lesion and rupture of C5, C6 and C7. Repair was undertaken at 14 weeks of age using both sural nerves. He had a good result: shoulder 6, 15; elbow 5, hand 5. Dislocation of the shoulder was diagnosed at the age of 18 months and corrected by open reduction at 22 months.

ion of the elbow was limited. The operation achieved its aim in 41 nerves (55\%) (Fig. 1).

C7. There were 29 repairs in 54 unfavourable lesions, of which 21 were complete avulsions. The results for repair of this nerve were particularly poor. The aim of operation, which was to achieve functional extension of the wrist and fingers, was attained in only seven $(24 \%)$ of repaired nerves. There were 25 unfavourable lesions of $\mathrm{C} 7$ which were not repaired because recovery was hoped for or because higher priority was given to function of the shoulder and hand. We were unable to demonstrate any difference in outcome between the repaired and unrepaired nerves.

C8 and T1. There were 47 repairs in 80 unfavourable lesions of which 48 were complete avulsions. Repairs were not carried out in any case where some function or recovery was demonstrated at operation. Repairs were confined to examples of complete avulsion (type 5). In some exceptionally severe cases of avulsion of three or four nerves only one was repaired, usually C8. The results were good in 27 repairs $(57 \%)$, there was some recovery in 17 more and the operation failed in three. 


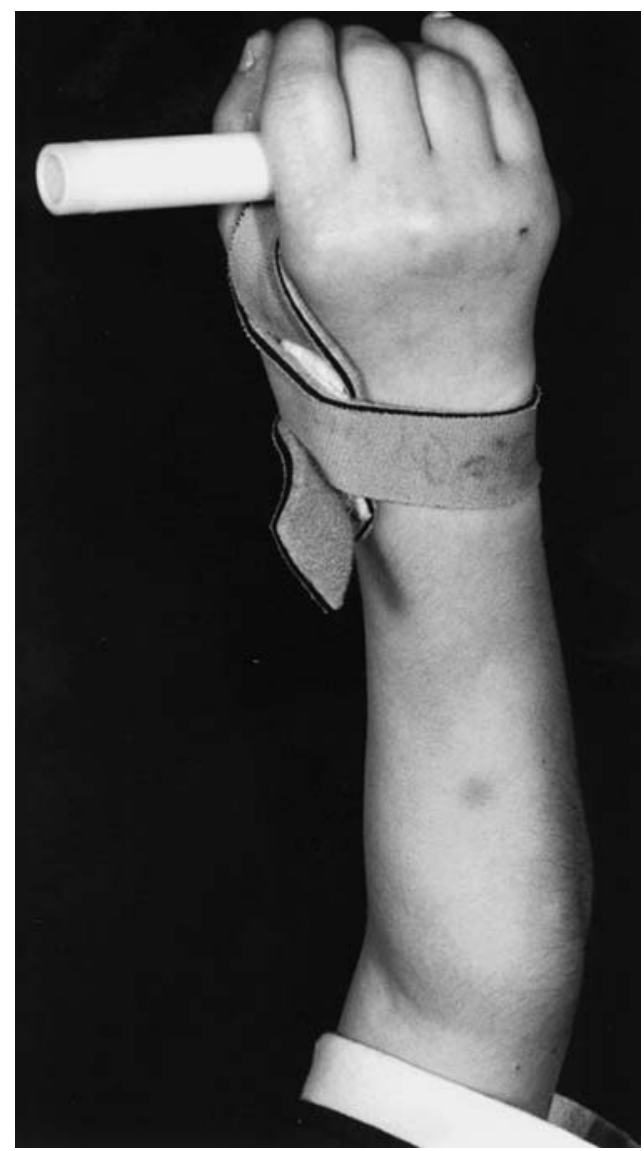

Fig. 2

Photograph of a ten-year-old boy who had a group 4 lesion with rupture of $\mathrm{C} 5$ and $\mathrm{C} 6$, avulsion of $\mathrm{C} 7, \mathrm{C} 8$ and T1. Repair was undertaken at four months of age. C6 was transferred to the lower truck. The upper trunk was re-innervated by $\mathrm{C} 5$. Accessory to suprascapular transfer was carried out. One graft was placed from $\mathrm{C} 5$ to the distal stump of C7. At eight years of age, shoulder function was graded at $2+($ Mallett 10 ) elbow at 4 and hand 4. Recovery for C7 was particularly poor, a simple orthosis enhanced abduction of the thumb.

The primary object of repair in Narakas groups 1 (2), 2 (36) and nearly all in group 3 (12) was restoration of function at the shoulder and the elbow. In the 50 group 4 cases, we aimed to restore hand function. We have analysed the outcome of repair of C5 and C6 roots, which represent 161 of the total of 237 repaired spinal nerves, against the depth of the lesion because hand function was normal, or at least useful, in the 1, 2 and 3 groups. The results are set out in Table VII. There appears to be a trend towards worsening of the outcome for repairs of both C5 and C6 in group 4. The figures are too small to permit statistical analysis. One possible reason for this trend, which was not as strong as we had anticipated, is the general depression of the power of neurological recovery in more extensive lesions; another is the varying reliability of the different methods of repair. There were few good results from intraplexus transfer for shoulder and elbow function, perhaps because one spinal nerve which has suffered post-ganglionic rupture is required to re-innervate two segments within the upper limb. Transfer of intercostal to musculocutaneous nerves for elbow flexion was disappointing, with failure in three of four cases. However, restoration of sensation within the hand by intercostal transfer to the lateral cord was remarkably good (Fig. 2). ${ }^{26}$

\section{Complications}

During the procedures the phrenic nerve was damaged twice. It was repaired in both but one of these infants required plication of the hemi-diaphram. This particularly serious complication is life threatening and the utmost care is needed in defining and protecting the nerve. Two children developed pressure sores from the plaster cowl. There was no deep infection; there were two cases of superficial wound infection which responded to treatment with antibiotics.

Two babies, operated on early in the series, required blood transfusion of 30 and $50 \mathrm{ml}$, respectively.

\section{Discussion}

Early repair of the post-ganglionic ruptures of C5 and of $\mathrm{C} 6$ in closed traction lesions in adults gives a good functional outcome. ${ }^{32}$ The results set out here are scarcely any better. However, restoration of useful hand function in complete lesions in adults is seen only rarely, but just over one half of babies having avulsions of C8 and T1 due to obstetric brachial plexus palsy regained useful hand function. Normal sensation never returns in the hand after repair of the adult brachial plexus but most of those with obstetric brachial plexus palsy recovered normal sensation. No child in this series had neuropathic pain.

Dislocation of the shoulder has an adverse effect on the functional expression of neurological recovery. Even in those treated successfully there was a loss of function which was statistically significant compared to those without dislocation.

Our results for repairs of individual nerves were not regularly reliable. In C5 the outcome was acceptable in about $70 \%$. The outcome of operation in cases of rupture of C6 was more uncertain. Failure of recovery of elbow flexion in untreated cases of obstetric brachial plexus palsy is extremely rare. Apart from three cases of severe birth damage to the biceps muscle, the only examples of failure of recovery of functional flexion of the elbow in more than 1500 cases referred to our unit were seen in children in whom C6 had been repaired. The results of repairs of C7 were particularly poor. This nerve seems to be prone to longitudinal injury with a high incidence of mixed rupture and of partial intradural damage. ${ }^{33}$ In complete avulsions of C8 and T1 intraplexus transfer offers the only prospect for recovery of function in the hand. No useful hand function can occur by spontaneous recovery.

We operate now on a relatively small group of lesions. Exploration and repair should be done in breech babies with phrenic palsy and at no later than eight weeks in com- 
plete group 4 lesions where neurophysiological and radiological evidence points to a pre-ganglionic injury. Operation is indicated in groups 1 and 2 (C5, C6 and C5, C6 and $\mathrm{C} 7)$ when neurophysiological type $\mathrm{C}$ or B (unfavourable) is found for C5 and type C for C6 and for C7. Increasingly, we leave alone the neuroma of the upper trunk from post ganglionic rupture, and prefer specific extra-plexus transfers such as the accessory to the suprascapular nerve and the ulnar nerve to the biceps.

The authors choose not to respond to the request for a conflict of interest statement.

\section{References}

1. Kennedy R. Suture of the brachial plexus in birth paralysis of the upper extremity. $\mathrm{Br}$ Med J 1903;1:298-301.

2. Clark LP, Taylor AS, Prout TP. A study in brachial birth palsy. Am J Med Sci 1905; 130:670-707.

3. Taylor AS. Brachial birth palsy and injuries of a similar type in adults. Surg Gyn Obs 1920;30:494-502.

4. Wyeth JA, Sharpe W. The field of neurological surgery in a general hospital. Gyn Obs 1917;24:29-36.

5. Fairbank HAT. Subluxation of shoulder joint in infants and young children. Lancet 1913;1:1217-23

6. Sever JW. Obstetrical paralysis: report of eleven hundred cases. J Am Med Ass 1925;85:1862-5

7. Jepson PN. Obstetrical paralysis. Ann Surg 1930;91:724-30.

8. Narakas A0. Brachial plexus surgery. Orthop Clin North Am 1981;12:303-22.

9. Morelli E, Raimondi PL, Saporiti E. II loro trattamenot precoce. In: Pipino F, ed. Le paralisi ostetriche. Bologna: Auto gaggi, 1984:57-76.

10. Narakas A. Obstetrical brachial plexus injuries.. In: Lamb DW, ed. The paralysed hand. Edinburgh: Churchill Livingstone, 1987:116-35

11. Evans-Jones G, Kay SPJ, Weindling AM, et al. Congenital brachial palsy: incidence, causes and outcome in the United Kingdom and Republic of Ireland. Arch Dis Fetal Neonatal 2003;88:185-9.

12. Bisinella G, Birch R. Obstetric brachial plexus lesion: a study of 74 children registered with the British Surveillance Unit. J Hand Surg [Br] 2002;38:40-5.

13. Tassin JL. Paralysies obstétricales du plexus brachial: evolution spontanée, résultats des interventions éparatrices précoces. Thèse. Universite Paris VII, 1983.

14. Laurent JP, Lee R, Shenaq S, et al. Neurosurgical correction of upper brachia plexus birth injuries. Neurosurg 1993;79:197-203.
15. Michelow BJ, Clarke HM, Curtis CG, et al. The natural history of obstetrical brachial plexus palsy. Plast Reconstr Surg 1994;93:675-80.

16. Clarke HM, Curtis C. Examination and prognosis. In: Gilbert A, ed. Brachial plexus injuries. London: Martin Dunitz in association with the Federation of European Societies for Surgery of the Hand, 2001;12:159-72.

17. Nehme A, Kany J, Sales-de-Gauzy J, et al. Obstetrical brachial plexus palsy, predictions of outcome in upper root injuries. J Hand Surg [Br] 2001;27:9-12.

18. Slooff ACJ, Blaauw G. Aspects particuliers. In: Alnot J-Y, Narakas A, eds. Les paralysies du plexus brachial. Second ed. Monographie de la Société Français de Chirurgie de la Main. Expansion Scientifique Français, 1995:282-4.

19. Blaauw G, Slooff ACJM, Muhlig S. Results of surgery after breech delivery. In: Gilbert A, ed. Brachial plexus injuries. London: Martin Dunitz, 2002:217-24.

20. Smith SJM. The role of neurophysiological investigation in traumatic brachial plexus injuries in adults and children. J Hand Surg [Br] 1996;21:145-8.

21. Smith SJM. Electrodiagnosis. In: Birch R, Bonney G, Wynn Parry CB, eds. Surgical disorders of the peripheral nerves. First ed. London: Churchill Livingstone, 1998;19: 467-90.

22. Bisinella G, Birch R, Smith SJM. Neurophysiological predictions of outcome in obstetric lesions of the brachial plexus. J Hand Surg [Br] 2003;28:148-52.

23. Gilbert A. Paralysie obstetricale du plexus brachial. In: Alnot JY, Narakas A, eds. Les paralysies du plexus brachial. Second ed. Monographie de la Societé Français de Chirurgie de la Main. Expansion Scientifique Français, 1995:270-81.

24. Gilbert A. Results of repair to the obstetrical plexus. In: Gilbert A, ed. Brachial plexus injuries federation of european societies for surgery of the hand. 2002:211-15.

25. Chen L. Results of repair in 65 cases. In: Birch R, Bonney G, Wynn Parry CB, eds. Surgical disorders of the peripheral nerves. First ed. London: Churchill Livingstone, 1998: 221-2.

26. Anand P, Birch R. Restoration of sensory function and lack of long-term chronic pain syndromes after brachial plexus injury in human neonates. Brain 2002;125:113-22.

27. Birch R, Bonney G, Wynn Parry CB. Birth lesions of the brachial plexus. In: Surgical disorders of the peripheral nerves. First ed. London: Churchill Livingstone, 1998 216-19.

28. Gilbert A. Evaluation of results in obstetrical brachial plexus palsy. Procs International Meeting on Obstetric Brachial Plexus Palsy, 2003.

29. Mallett J. Paralysie obstetricale du plexus brachial. Rev Chir Orthop 1972;58:115-204.

30. Gilbert A, Raimondi P. A system of evaluation of elbow flexion. Procs International Meeting on Obstetric Brachial Plexus Palsy, 1993.

31. Raimondi P. Evaluation of the hand. Procs International Meeting on Obstetric Brachial Plexus Palsy, 1993

32. Birch R, Bonney G, Wynn Parry CB. Traumatic lesions of the brachial plexus. In: Surgical disorders of the peripheral nerves. First ed. London: Churchill Livingstone, 1998: 216-19.

33. Schenker M, Birch R. Diagnosis of level of intradural ruptures of the rootlets in traction lesions of the brachial plexus. J Bone Joint Surg [Br] 2001;83-B:916-20. 